\title{
Plasma Free Amino Acid Responses to Intraduodenal Whey Protein, and Relationships with Insulin, Glucagon-Like Peptide-1 and Energy Intake in Lean Healthy Men
}

\author{
Natalie D. Luscombe-Marsh ${ }^{1,2, *}$, Amy T. Hutchison ${ }^{1}$, Stijn Soenen ${ }^{1}$, Robert E. Steinert ${ }^{1}$, \\ Peter M. Clifton ${ }^{1,3}{ }^{\text {, Michael Horowitz }}{ }^{1}$ and Christine Feinle-Bisset ${ }^{1}$ \\ Received: 21 October 2015; Accepted: 14 December 2015; Published: 4 January 2016 \\ 1 NHMRC Centre of Research Excellence in Translating Nutritional Science to Good Health, \\ The University of Adelaide Discipline of Medicine, Adelaide 5000, Australia; \\ amy.hutchison@adelaide.edu.au (A.T.H.); stijn.soenen@adelaide.edu.au (S.S.); \\ robert.steinert@adelaide.edu.au (R.E.S.); Peter.Clifton@unisa.edu.au (P.M.C.); \\ michael.horowitz@adelaide.edu.au (M.H.); christine.feinle@adelaide.edu (C.F.-B.) \\ CSIRO Food and Nutrition, PO Box 10041 Adelaide BC, Adelaide SA 5000, Australia \\ 3 School of Pharmacology and Medical Sciences, University of South Australia, Adelaide 5001, Australia \\ * Correspondence: natalie.luscombe-marsh@csiro.au; Tel.: +61-8-83050605; Fax: +61-8303-8899
}

\begin{abstract}
This study determined the effects of increasing loads of intraduodenal (ID) dairy protein on plasma amino acid (AA) concentrations, and their relationships with serum insulin, plasma glucagon-like peptide-1 (GLP-1) and energy intake. Sixteen healthy men had concentrations of AAs, GLP-1 and insulin measured in response to 60-min ID infusions of hydrolysed whey protein administered, in double-blinded and randomised order, at 2.1 (P2.1), 6.3 (P6.3) or 12.5 (P12.5) kJ/min (encompassing the range of nutrient emptying from the stomach), or saline control (C). Energy intake was quantified immediately afterwards. Compared with C, the concentrations of 19/20 AAs, the exception being cysteine, were increased, and this was dependent on the protein load. The relationship between AA concentrations in the infusions and the area under the curve from 0 to $60 \mathrm{~min}$ $\left(\mathrm{AUC}_{0-60 \mathrm{~min}}\right)$ of each AA profile was strong for essential AAs ( $R^{2}$ range, $\left.0.61-0.67\right)$, but more variable for non-essential (0.02-0.54) and conditional (0.006-0.64) AAs. The $\mathrm{AUC}_{0-60 \text { min }}$ for each AA was correlated directly with the $\mathrm{AUC}_{0-60 \text { min }}$ of insulin ( $R^{2}$ range $\left.0.3-0.6\right)$, GLP-1 (0.2-0.6) and energy intake (0.09-0.3) $(p<0.05$, for all), with the strongest correlations being for branched-chain AAs, lysine, methionine and tyrosine. These findings indicate that ID whey protein infused at loads encompassing the normal range of gastric emptying increases plasma concentrations of 19/20 AAs in a load-dependent manner, and provide novel information on the close relationships between the essential AAs, leucine, valine, isoleucine, lysine, methionine, and the conditionally-essential AA, tyrosine, with energy intake, insulin and GLP-1.
\end{abstract}

Keywords: dairy; whey protein hydrolysate; insulinotropic response; glycemic control; appetite regulation; human

\section{Introduction}

Calorie-controlled diets with moderately increased protein content are effective in the management of obesity due to their capacity to (i) suppress appetite [1] and, under ad-libitum feeding conditions, reduce energy intake [2]; (ii) promote loss of fat while preserving muscle mass [3,4]; (iii) increase insulin release and reduce postprandial glycemic excursions [1,3]; and (iv) improve lipid 
metabolism and blood pressure [1,3]. These benefits, however, are often not sustained for more than 12 months, and hence, greater understanding of the mechanisms underlying these benefits is required.

Oral and intraduodenal (ID) administration of dietary protein, including whey protein isolate (in both un-hydrolysed and hydrolysed form), like lipid and carbohydrate, modulates gastrointestinal (GI) motor activity and hormone release in a nutrient load-dependent manner [5-7]. In turn, these GI factors influence gastric emptying [8], postprandial glycaemia [9] and energy intake [5-7]. While whey protein isolate, co-ingested with carbohydrate, improves glycaemia by slowing gastric emptying and stimulating the release of glucagon-like peptide-1 (GLP-1) and/or glucose-dependent insulinotropic polypeptide (GIP) as well as insulin [10], our recent observations indicate that the effects of lipid-protein combinations on these gut hormones are related directly to the amount of lipid, and the effects on insulin and glucagon are related to the amount of protein, whereas the effects on energy intake appear dependent on a threshold load of $\sim 12.5 \mathrm{~kJ} / \mathrm{min}$ (or $3 \mathrm{kcal} / \mathrm{min}$ ) of either nutrient being delivered to the duodenum [11]. This study also demonstrated that the effects of ID infused hydrolysed whey protein isolate (which did not contain fat or carbohydrate and was delivered at $12.5 \mathrm{~kJ} / \mathrm{min}$ ) on the GI factors were weaker than those of isocaloric lipid [11] suggesting the suppression of energy intake by protein may be dependent on additional mechanisms.

Several studies have reported modest associations between increased postprandial plasma essential amino acid (AA) concentrations, particularly the branched chain AAs, leucine, isoleucine and valine, with either an increased release of some gut hormones (particularly GLP-1 and GIP), insulin, or reduced energy intake [12-14]. Moreover, there is some evidence that other essential AAs, including lysine, threonine, phenylalanine, tryptophan, histidine, the conditionally-essential AAs, glutamine, arginine and tyrosine, and the non-essential AA, glutamate, may activate peripheral and central mechanisms involved in the regulation of energy intake and glucose homeostasis, although information is limited [15].

The aims of this study were to determine: (1) the effects of increasing loads of hydrolysed whey protein administered ID (thus mimicking the entry of the nutrient into the duodenum and bypassing any orosensory influences and inter-individual variations in gastric emptying), at rates reflective of the normal range of gastric emptying, on plasma concentrations of free AAs that were present within the whey; and (2) the relationships between plasma AA concentrations with insulin and GLP-1 concentrations and energy intake, outcomes that we have previously reported [7]. We hypothesised that hydrolysed whey protein infused ID at loads lower than $(2.1 \mathrm{~kJ} / \mathrm{min}(\mathrm{P} 2.1))$, similar to $(6.3 \mathrm{~kJ} / \mathrm{min}$ (P6.3)), and toward the upper end (12.5 kJ/min (P12.5)), of normal gastric emptying rates would modulate the release of free AAs into the blood in a load-related manner, and leucine, isoleucine, valine, and potentially other AAs, would be related to the insulin and GLP-1 responses and energy intake.

\section{Subjects and Methods}

\subsection{Subjects}

Sixteen healthy lean men (mean age $27 \pm 3$ years, range 19-54 years; BMI $22.1 \pm 0.6 \mathrm{~kg} / \mathrm{m}^{2}$; range $18.5-24.8 \mathrm{~kg} / \mathrm{m}^{2}$ ) participated in the study, as described [7]. In addition to the original power calculation [7], we calculated that $n=16$ would allow us to detect relationships of $r \geqslant 0.5$ between increasing loads of protein with total plasma AAs, and increasing plasma total AA concentrations with energy intake, plasma insulin and GLP-1 [5,6]. The Royal Adelaide Hospital Research Ethics Committee approved the study protocol, and the study was registered as a clinical trial with the Australia and New Zealand Clinical Trial Registry (www.anzctr.org.au, registration number 12610000376044). All subjects provided written, informed consent, prior to their inclusion.

\subsection{Study Outline}

While the aim of the original study was to evaluate the effects of increasing loads of ID infusion of hydrolysed whey protein at loads of (i) $2.1 \mathrm{~kJ} / \mathrm{min}$ "P2.1"; (ii) $6.3 \mathrm{~kJ} / \mathrm{min}$ "P6.3"; or (iii) $12.5 \mathrm{~kJ} / \mathrm{min}$ 
"P12.5"; or (iv) a saline control "C", at a rate of $4 \mathrm{~mL} / \mathrm{min}$ for $60 \mathrm{~min}$, on antropyloroduodenal motility (APD), and gut hormone, insulin, glucose, appetite and energy intake responses [7], we have now evaluated the effects on plasma free AAs to determine their relationships with GLP-1, insulin, and energy intake [7].

\subsection{Intraduodenal Infusions}

The infusion solutions were prepared as described [7]. In brief, hydrolysed whey protein (Whey Protein Hydrolysate 821, Fonterra Co-Operative Group Ltd, Auckland, New Zealand) was dissolved in varying amounts of saline and water to achieve the desired loads (i.e., 2.1, 6.3 and $12.5 \mathrm{~kJ} / \mathrm{min}$, which equated to 8,24 and $48 \mathrm{~g}$ of protein over $60 \mathrm{~min}$ ) and to ensure they were all a total volume of $240 \mathrm{~mL}$ and equi-osmolar ( 640-676 mOsmol/L). As a component of dairy products, whey protein is common in the diet and has been shown to be the most satiating protein source when consumed orally $[16,17]$. We have used whey protein in our previous studies evaluating the role of macronutrients on GI function and appetite [7,10,11]. Hydrolysed whey was selected because it contains di- and tri-peptide fractions as well as larger peptides and some amino acids, and hence, more closely resembles partially digested protein, that would be entering the small intestine following oral protein ingestion [18,19]. Infusions were prepared on the morning of each study by an investigator who was not involved in the data analysis. The infusion apparatus was covered at all times so that both the primary investigator and the subject were blinded to the treatment. Table 1 depicts the specific AA composition of the hydrolysed whey protein.

Table 1. The amino acid (AA) composition of the whey protein infusion solutions ${ }^{a, b, c}$.

\begin{tabular}{cccc}
\hline \multirow{3}{*}{ AA } & \multicolumn{3}{c}{ Treatment } \\
\cline { 2 - 4 } & $\mathbf{P 2 . 1}$ & $\mathbf{P 6 . 3}$ & $\mathbf{P 1 2 . 5}$ \\
\hline Glutamic acid & $1.3(36.3)$ & $3.8(108.9)$ & $7.7(217.8)$ \\
Leucine & $0.9(29.7)$ & $2.8(89.1)$ & $5.6(178.2)$ \\
Aspartic acid & $0.8(26.5)$ & $2.5(79.3)$ & $5.1(158.7)$ \\
Lysine & $0.8(23.4)$ & $2.5(70.3)$ & $5.0(140.5)$ \\
Alanine & $0.4(20.8)$ & $1.3(62.4)$ & $2.7(124.8)$ \\
Valine & $0.4(14.7)$ & $1.2(44.2)$ & $2.5(88.4)$ \\
Proline & $0.4(14.5)$ & $1.2(43.4)$ & $2.4(86.9)$ \\
Isoleucine & $0.4(14.1)$ & $1.3(42.4)$ & $2.7(84.8)$ \\
Threonine & $0.4(13.2)$ & $1.1(39.5)$ & $2.3(79.1)$ \\
Serine & $0.3(9.9)$ & $0.8(29.6)$ & $1.5(59.2)$ \\
Phenylalanine & $0.3(7.8)$ & $0.9(23.4)$ & $1.9(46.7)$ \\
Tyrosine & $0.3(7.3)$ & $0.9(21.9)$ & $1.9(43.7)$ \\
Arginine & $0.3(5.9)$ & $0.8(17.8)$ & $1.5(35.7)$ \\
Glycine & $0.2(10.5)$ & $0.6(31.4)$ & $1.1(62.8)$ \\
Cysteine & $0.2(6.5)$ & $0.6(19.5)$ & $1.1(38.9)$ \\
Methionine & $0.2(4.9)$ & $0.5(14.5)$ & $1.0(29.1)$ \\
Histidine & $0.2(4.7)$ & $0.5(14.0)$ & $1.0(28.0)$ \\
Tryptophan & $0.2(3.9)$ & $0.6(11.6)$ & $1.1(23.1)$ \\
Glutamine & & Not reported \\
Asparagine & & Not reported \\
Total & $8.0(254)$ & $24.0(763)$ & $48.0(1526)$ \\
\hline
\end{tabular}

\footnotetext{
a The amino acid (AA) composition of "Hydrolysed Whey Protein 821" was provided by Fonterra Co-Operative Group Ltd, Auckland, New Zealand, and glutamine and asparagine were not reported in protein product specification; ${ }^{b}$ The infusions (total volume $240 \mathrm{~mL}$ ) consisted of $2.1 \mathrm{~kJ} / \mathrm{min}(\mathrm{P} 2.1), 6.5 \mathrm{~kJ} / \mathrm{min}$ (P6.3), or $12.5 \mathrm{~kJ} / \mathrm{min}$ (P12.5) of whey protein, each infused at $4 \mathrm{~mL} / \mathrm{min}$ for $60 \mathrm{~min} ;{ }^{\mathrm{C}}$ The AAs are presented in order of most to least abundant $g$ present within the protein infusions and glutamic acid and aspartic acid include the contribution from asparagines and glutamine in this product specification.
} 
Subjects were studied on four occasions, each separated by 3-10 days, in a randomized, double-blind, cross-over design. Randomisation was performed by an investigator not involved in the assessments using the free software "Research Randomiser", and the investigator performing the assessments was blinded to the randomisation and preload conditions. Subjects were provided with a standardised evening meal to consume the night prior to each study day, and were instructed to abstain from all food and drinks and to refrain from strenuous physical activity, until attending the laboratory at the Discipline of Medicine at 8:30 a.m. Upon arrival, a small-diameter (OD: $3.5 \mathrm{~mm}$ ) manometric catheter (total length: $100 \mathrm{~cm}$, Dentsleeve International, Mui Scientific, Mississauga, ON, Canada) was inserted into the stomach through an anesthetised nostril and allowed to pass into the duodenum by peristalsis. The catheter contained 16 side-holes spaced at $1.5 \mathrm{~cm}$ intervals, with an additional channel used for ID infusions located $11.75 \mathrm{~cm}$ distal to the end of the sleeve sensor (14.5 $\mathrm{cm}$ from the pylorus), and was positioned as described previously [7]. Once the catheter was positioned correctly (which took between 15 and $45 \mathrm{~min}$ ), fasting motility was monitored until the occurrence of a phase III of the interdigestive migrating motor complex. Immediately after cessation of phase III activity, an intravenous cannula was placed in a right forearm vein for blood sampling. At $t=-15$ min (during motor quiescence, i.e., phase I of the migrating motor complex), a baseline blood sample $(14 \mathrm{~mL})$ was taken and a visual analogue scale questionnaire (VAS) to assess appetite perceptions and GI symptoms completed by the subject. Baseline measurement of APD motility also commenced. At $t=0 \mathrm{~min}$, the 60-min ID infusion of one of the treatments commenced. During the infusion, APD motility was monitored continuously, and VAS ratings and blood samples were obtained at $15-\mathrm{min}$ intervals. At $t=60 \mathrm{~min}$, the infusion was terminated and the ID catheter removed. Subjects were then presented with a standardised cold, buffet-style meal, in excess of what they would be expected to consume, and instructed to eat freely for up to $30 \mathrm{~min}(t=60-90 \mathrm{~min})$ until comfortably full [20]. The composition of the buffet meal has been described [20].

\subsection{Measurements}

Plasma free AA and GLP-1 and serum insulin concentrations: 10-mL venous blood samples were collected in ice-chilled EDTA-treated tubes for plasma AA and GLP-1 analysis, and 4-mL samples in serum-Z tubes containing clotting beads (Sarstedt Australia Pty Ltd, Adelaide, Australia) for insulin. Plasma/serum was separated by centrifugation at $3200 \mathrm{rpm}$ for $15 \mathrm{~min}$ at $4{ }^{\circ} \mathrm{C}$, and stored at $-70^{\circ} \mathrm{C}$ for later analysis. Plasma free AAs concentrations $(\mathrm{mmol} / \mathrm{L})$ of asparagine, aspartic acid, alanine, arginine, cysteine, glutamine, glutamic acid, glycine, histidine, isoleucine, leucine, lysine, methionine, phenylalanine, proline, serine, threonine, tryptophan, tyrosine and valine, were analysed using precolumn derivatization with 6-aminoquinolyl-N hydroxysuccmimidyl carbamate (AQC). The derivatives were then separated and quantified by reversed-phase high-performance liquid chromatography (HPLC). The AAs (with the exception of tryptophan) were detected by fluorescence, whereas tryptophan required UV detection. Before derivatisation, $100 \mu \mathrm{L}$ of plasma samples were diluted 1:1 with internal standard solution (Norvaline) and deproteinised by ultra-filtration through a membrane with $10 \mathrm{kDa}$ nominal molecular weight cut-off (Ultrafree MC with PL-10 membrane, Millipore, MA, USA). AAs contained in the filtrate $(100 \mu \mathrm{L})$ were labelled using the Waters AccQTag ${ }^{\mathrm{TM}}$ chemistry and analysed using a Waters Acquity ${ }^{\mathrm{TM}}$ UPLC system (Waters Corporation, MA, USA) [21]. Only single analysis of each AA was conducted. The analysis was performed at the Australian Proteome Analysis's Facility established under the Australian Government's National Collaborative Research Infrastructure Strategy (NCRIS). All analyses were performed by the same technician. Plasma GLP-1 (pmol/L) and serum insulin (mU/L) were measured, as described [7].

Energy intake: The amount eaten (g) was quantified by weighing the buffet meal before and after consumption, and energy (kJ) was then calculated using commercially available software (Foodworks, Xyris Software, version 3.01, Highgate Hill, Australia). 


\subsection{Data and Statistical Analyses}

Statistical analyses were performed using SPSS software (version 19.0; SPSS Inc, IBM, New York, NY, USA). Baseline plasma AA concentrations were analysed using one-way ANOVA with protein load as the within-subject factor. The effect of protein load on the net incremental area under the curve $\left(\mathrm{AUC}_{0-60 \mathrm{~min}}\right.$ ) for each AA (calculated using the trapezoidal rule) was analysed by one-way ANOVA with protein load as the fixed factor. Post-hoc comparisons, adjusted for multiple comparisons using Bonferroni's correction, were performed when ANOVAs revealed significant effects. The effects of increasing loads of protein on insulin and GLP-1 concentrations and on energy intake at a subsequent meal have been reported [7], and additional analyses of the AUC for insulin and GLP-1 were done to determine relationships between these outcomes with the AUC for each of the 20 AAs. Relationships between the AUC for each AA and either protein load, total AA concentration within the infusion, energy intake or AUC for insulin and GLP-1, respectively, were evaluated using linear within-subject correlations ( $r$ ) with AUC for each AA profile as the dependent, subject as a fixed factor and the other variable as a covariate. Relationships between each AA with energy intake and AUCs for insulin and GLP-1, respectively, were ranked in order of strongest to weakest, using $R$ square values. Statistical significance was accepted at $p<0.05$; all data are presented as mean $\pm \mathrm{SEM}$.

\section{Results}

\subsection{Plasma AA Concentrations}

Baseline concentrations of individual and total AAs did not differ between test days (Table 2).

Table 2. Plasma amino acid (AA) concentrations at baseline prior to commencing each infusion ${ }^{\mathrm{a}, \mathrm{b}, \mathrm{c}}$.

\begin{tabular}{|c|c|c|c|c|c|}
\hline \multirow{2}{*}{ AA } & \multirow{2}{*}{$\mathrm{C}$} & \multicolumn{3}{|c|}{ Treatment } & \multirow{2}{*}{$p$ Value $^{\mathrm{c}}$} \\
\hline & & P2.1 & P6.3 & P12.5 & \\
\hline & \multicolumn{5}{|c|}{ umol/L } \\
\hline Glutamine & 520 & 530 & 540 & 540 & $>0.05$ \\
\hline Alanine & 240 & 240 & 240 & 270 & $>0.05$ \\
\hline Valine & 190 & 190 & 200 & 190 & $>0.05$ \\
\hline Glycine & 180 & 180 & 190 & 190 & $>0.05$ \\
\hline Proline & 150 & 150 & 150 & 160 & $>0.05$ \\
\hline Lysine & 150 & 150 & 150 & 150 & $>0.05$ \\
\hline Threonine & 200 & 100 & 100 & 100 & $>0.05$ \\
\hline Leucine & 100 & 100 & 100 & 100 & $>0.05$ \\
\hline Serine & 90 & 90 & 90 & 90 & $>0.05$ \\
\hline Glutamic acid & 80 & 90 & 90 & 90 & $>0.05$ \\
\hline Arginine & 80 & 80 & 80 & 80 & $>0.05$ \\
\hline Histidine & 60 & 70 & 70 & 70 & $>0.05$ \\
\hline Isoleucine & 50 & 50 & 50 & 50 & $>0.05$ \\
\hline Tyrosine & 50 & 50 & 50 & 50 & $>0.05$ \\
\hline Asparagine & 40 & 50 & 50 & 50 & $>0.05$ \\
\hline Phenylalanine & 40 & 40 & 40 & 40 & $>0.05$ \\
\hline Methionine & 020 & 20 & 20 & 20 & $>0.05$ \\
\hline Aspartic acid & 3 & 3 & 3 & 3 & $>0.05$ \\
\hline Tryptophan & 3 & 3 & 3 & 3 & $>0.05$ \\
\hline Cysteine & 2 & 2 & 2 & 2 & $>0.05$ \\
\hline Total & 2130 & 2200 & 2200 & 2230 & $>0.05$ \\
\hline
\end{tabular}

a Data are means, and the amino acids (AAs) have been presented in order of most to least concentrated, $n=16$;

$\mathrm{b}$ The infusions consisted of either saline (C), or of $2.1 \mathrm{~kJ} / \mathrm{min}$ (P2.1), $6.5 \mathrm{~kJ} / \mathrm{min}(\mathrm{P} 6.3)$, or $12.5 \mathrm{~kJ} / \mathrm{min}$ (P12.5) of hydrolysed whey protein, each infused at $4 \mathrm{~mL} / \mathrm{min}$ for $60 \mathrm{~min} ;{ }^{\mathrm{C}}$ Main effect of protein load was determined by one-way ANOVA and post-hoc comparisons between two loads of protein were done using Bonferroni's correction; statistical significance was accepted at $p<0.05$. 
In response to increasing loads of ID whey protein, the greatest increases in plasma concentrations over the 60-min infusion were observed for aspartic acid, isoleucine, leucine, lysine and methionine (Figure 1), whereas the smallest increases were observed for glycine, glutamine, histidine, glutamic acid and cysteine (Figure 2). The $\mathrm{AUC}_{0-60 \mathrm{~min}}$ of each of the $20 \mathrm{AA}$ profiles in response to increasing protein loads are depicted in Table 3. There was a significant main effect of protein load on plasma concentrations of 19/20 AAs ( $p<0.001)$, with the exception of cysteine. Post hoc-analyses revealed that the $\mathrm{AUC}_{0-60 \text { min }}$ of plasma concentrations of $16 / 20 \mathrm{AAs}(p<0.05$ for all), except tryptophan, alanine, glycine and cysteine, were greater during P2.1 compared with $\mathrm{C}$. While the $\mathrm{AUC}_{0-60 \min }$ of the plasma concentrations of each of the 20 AAs did not differ between P2.1 and P6.3, the $\mathrm{AUC}_{0-60 \mathrm{~min}}$ of all AA profiles, apart from glutamic acid, glycine and cysteine, were greater during P12.5 than during P2.1 ( $p<0.05$ for all). In addition, the $\mathrm{AUC}_{0-60 \text { min }}$ of 11/20 AAs, the exceptions being aspartic acid, threonine, asparagine, alanine, serine, glutamic acid, glutamine, glycine and cysteine, were greater during P12.5 than during P6.3 ( $p<0.05$ for all).

Table 3. Plasma amino acid (AA) responses $\left(\mathrm{AUC}_{0-60 \mathrm{~min}}\right)$ ordered from the strongest to weakest response following the infusions, relative to control ${ }^{\mathrm{a}, \mathrm{b}, \mathrm{c}}$.

\begin{tabular}{|c|c|c|c|c|c|}
\hline \multirow{2}{*}{ AA } & \multirow{2}{*}{$\mathrm{C}$} & \multicolumn{3}{|c|}{ Treatment } & \multirow{2}{*}{$p$ Value } \\
\hline & & P2.1 & P6.3 & P12.5 & \\
\hline & \multicolumn{5}{|c|}{ $\mu m o l .60 \mathrm{~min} / L$} \\
\hline Aspartic acid & 200 & $300^{d, e}$ & $500^{d}$ & $7000^{d}$ & $<0.001$ \\
\hline Isoleucine & 3200 & $6200 \mathrm{~d}, \mathrm{e}$ & $8600^{\mathrm{d}, \mathrm{e}}$ & $12,100^{\mathrm{d}}$ & $<0.001$ \\
\hline Leucine & 6100 & $11,700^{\mathrm{d}, \mathrm{e}}$ & $15,900^{\mathrm{d}, \mathrm{e}}$ & $21,900^{\mathrm{d}}$ & $<0.001$ \\
\hline Lysine & 9000 & $14,000^{\mathrm{d}, \mathrm{e}}$ & $18,000^{\mathrm{d}, \mathrm{e}}$ & $22,800^{\mathrm{d}}$ & $<0.001$ \\
\hline Methionine & 1100 & 1700 d,e & $2100 \mathrm{~d}, \mathrm{e}$ & $2900^{d}$ & $<0.001$ \\
\hline Tryptophan & 2000 & $300^{e}$ & $300^{\mathrm{d}, \mathrm{e}}$ & $4000^{d}$ & $<0.001$ \\
\hline Tyrosine & 2800 & $3800^{d, e}$ & $4500^{\mathrm{d}, \mathrm{e}}$ & $5800^{d}$ & $<0.001$ \\
\hline Valine & 11,300 & $14,600^{\mathrm{d}, \mathrm{e}}$ & $17,500^{\mathrm{d}, \mathrm{e}}$ & $20,800^{d}$ & $<0.001$ \\
\hline Phenylalanine & 2500 & 3200 d,e & $3600 \mathrm{~d}, \mathrm{e}$ & $4500^{d}$ & $<0.001$ \\
\hline Threonine & 5800 & 7600 d,e & $9100^{d}$ & $10,500^{\mathrm{d}}$ & $<0.001$ \\
\hline Asparagine & 2700 & 3500 d,e & $4200^{d}$ & $4800^{\mathrm{d}}$ & $<0.001$ \\
\hline Proline & 8800 & $10,700^{\mathrm{d}, \mathrm{e}}$ & $12,100^{\mathrm{d}, \mathrm{e}}$ & $14,800^{\mathrm{d}}$ & $<0.001$ \\
\hline Alanine & 14,500 & $17,000^{\mathrm{e}}$ & $19,200^{\mathrm{d}}$ & $23,100^{d}$ & $<0.001$ \\
\hline Arginine & 4600 & 6100 d,e & $700^{d, e}$ & $8400^{d}$ & $<0.001$ \\
\hline Serine & 5200 & $6500 \mathrm{~d}, \mathrm{e}$ & $7400^{d}$ & $8000^{\mathrm{d}}$ & $<0.001$ \\
\hline Glutamic acid & 4900 & $6100^{d}$ & $6200^{d}$ & $7100^{d}$ & $<0.001$ \\
\hline Histidine & 3900 & 4500 d,e & $4800^{\mathrm{d}, \mathrm{e}}$ & $5100^{d}$ & $<0.001$ \\
\hline Glutamine & 31,900 & $35,100 \mathrm{~d}, \mathrm{e}$ & $36,700^{d}$ & $38,100^{\mathrm{d}}$ & $<0.001$ \\
\hline Glycine & 10,800 & 11,600 & $12,300^{d}$ & $12,800^{\mathrm{d}}$ & $<0.001$ \\
\hline Cysteine & 100 & 100 & 200 & 100 & $>0.05$ \\
\hline Total & 129,000 & $165,000 \mathrm{~d}, \mathrm{e}$ & $190,000^{\mathrm{d}, \mathrm{e}}$ & $225,000^{d}$ & $<0.001$ \\
\hline
\end{tabular}

\footnotetext{
a Data are means, and the amino acids (AAs) have been presented in order of most to least concentrated, $n=16$; $\mathrm{b}$ The infusions consisted of either saline (C), or of $2.1 \mathrm{~kJ} / \mathrm{min}(\mathrm{P} 2.1), 6.5 \mathrm{~kJ} / \mathrm{min}(\mathrm{P} 6.3)$, or $12.5 \mathrm{~kJ} / \mathrm{min}$ (P12.5) of hydrolysed whey protein, each infused at $4 \mathrm{~mL} / \mathrm{min}$ for $60 \mathrm{~min} ;{ }^{\mathrm{C}}$ Main effect of protein load was determined by one-way ANOVA, and post-hoc comparisons between two loads were done using Bonferroni's correction; statistical significance was accepted at $p<0.05$; ${ }^{\mathrm{d}}$ Significantly different from $\mathrm{C}(p<0.05)$; ${ }^{\text {e }}$ Significantly different from P12.5 $(p<0.05)$.
} 


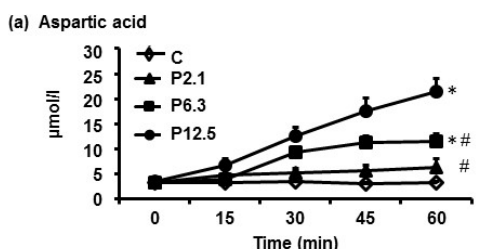

(c) Leucine
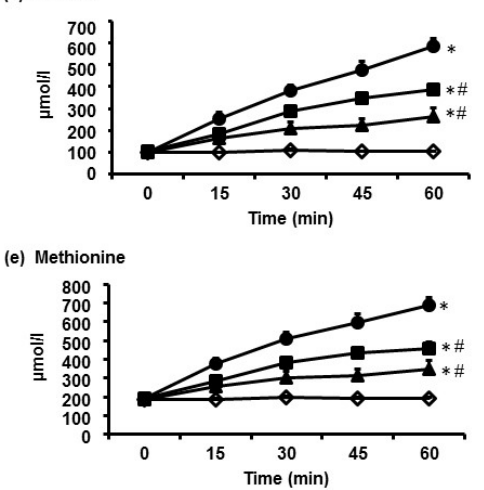

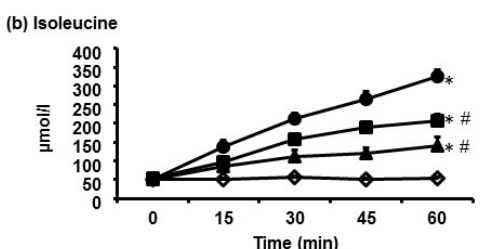

(d) Lysine

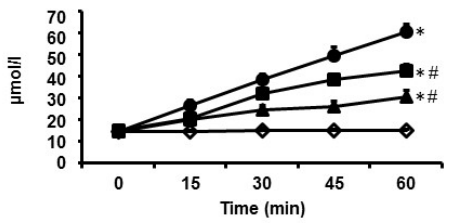

Figure 1. The temporal profiles of (a) aspartic acid; (b) isoleucine; (c) leucine; (d) lysine; and (e) methionine, the five amino acids whose plasma concentrations increased the most in response to increasing loads of ID protein. Data are means \pm SEM, $n=16$. The infusions consisted of either saline (C), or of $2.1 \mathrm{~kJ} / \mathrm{min}(\mathrm{P} 2.1), 6.5 \mathrm{~kJ} / \mathrm{min}$ (P6.3), or $12.5 \mathrm{~kJ} / \mathrm{min}$ (P12.5) of hydrolysed whey protein, each infused at $4 \mathrm{~mL} / \mathrm{min}$ for $60 \mathrm{~min}$. Main effect of protein load was determined by one-way ANOVA and post-hoc comparisons between two loads were done using Bonferroni's correction; statistical significance was accepted at $p<0.05$. ${ }^{*}$ Significantly different from C. \# Significantly different from P12.5 $(p<0.05)$
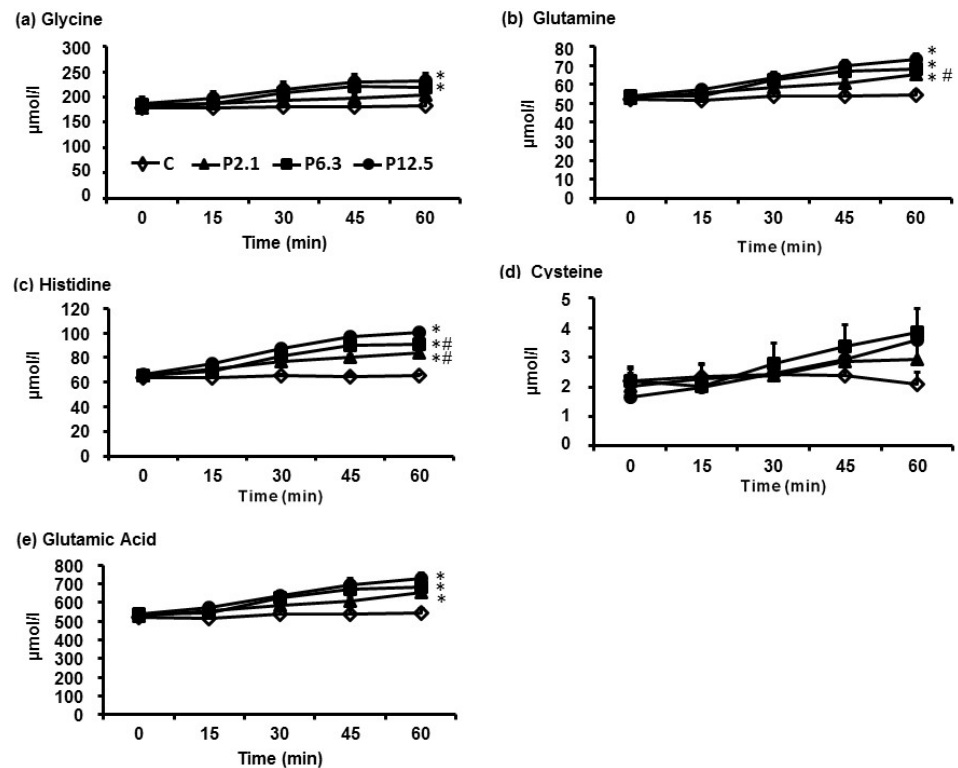

Figure 2. The temporal profiles of (a) glycine; (b) glutamine; (c) histidine; (d) cysteine; and (e) glutamic acid, the five amino acids whose plasma concentrations increased the least in response to increasing loads of ID protein. Data are means $\pm \mathrm{SEM}, n=16$; The infusions consisted of either saline (C), or of $2.1 \mathrm{~kJ} / \mathrm{min}$ (P2.1), $6.5 \mathrm{~kJ} / \mathrm{min}$ (P6.3), or $12.5 \mathrm{~kJ} / \mathrm{min}$ (P12.5) of hydrolysed whey protein, each infused at $4 \mathrm{~mL} / \mathrm{min}$ for $60 \mathrm{~min}$; Main effect of protein load was determined by one-way ANOVA and post-hoc comparisons between two loads were done using Bonferroni's correction; statistical significance was accepted at $p<0.05$. * Significantly different from C. \# Significantly different from P12.5 $(p<0.05)$. 
Strong positive relationships between protein load and the resultant $\mathrm{AUC}_{0-60 \text { min }}$ of the plasma concentrations of all essential AAs were evident (i.e., range of $R^{2}$ values was $0.58-0.69 ; p<0.001$ for all), whereas the strength of the relationships was more variable for non-essential (i.e., $0.28-0.55 ; p<0.05$ for all) and conditional (i.e., 0.01-0.66; $p<0.05$ for all) AAs. In addition, plasma concentrations of essential AAs reflected closely their concentrations in the infused whey protein (i.e., range of $R^{2}$ values was $0.61-0.67 ; p<0.001$ for all), whereas the relationships were more variable for non-essential (i.e., $0.02-0.54 ; p<0.001$ for all) and conditional (i.e., $0.006-0.64 ; p<0.01$ for all; the exception being cysteine which was not related) AAs.

\subsection{Serum Insulin and Plasma GLP-1 Concentrations, and Energy Intake and Amount of Food Consumed at the Buffet Meal}

For the purpose of the current analysis, the temporal profiles of insulin and GLP-1 that were reported previously [7] have been expressed as AUCs. Table 4 depicts the AUCs $\mathrm{s}_{0-60 \min }$ of the serum insulin, and plasma GLP-1, concentrations, and energy intake and the amount of food consumed at the buffet meal, in response to increasing loads of protein.

Table 4. Serum insulin and plasma GLP-1 responses $\left(\mathrm{AUCs}_{0-60 \mathrm{~min}}\right)$, and energy intake and amount of food consumed at the buffet meal, in response to increasing loads of ID protein ${ }^{a, b, c}$.

\begin{tabular}{cccccc}
\hline $\begin{array}{c}\text { Hormone and Food } \\
\text { Intake Response }\end{array}$ & C & P2.1 & P6.3 & P12.5 & $p_{\text {Value }}^{\text {c }}$ \\
\hline Insulin (mU.60min/L) & $150 \pm 19$ & $354 \pm 94^{\mathrm{d}}$ & $721 \pm 99^{\mathrm{d}}$ & $1087 \pm 145^{\mathrm{d}, \mathrm{e}}$ & $<0.05$ \\
GLP-1 (mmol.60min/L) & $1489 \pm 113$ & $1698 \pm 142$ & $2053 \pm 159^{\mathrm{d}, \mathrm{f}}$ & $2147 \pm 171^{\mathrm{d}, \mathrm{f}}$ & $<0.05$ \\
Energy intake (buffet; kJ) & $5173 \pm 464$ & $4981 \pm 473$ & $4504 \pm 523 \mathrm{~g}$ & $3814 \pm 502^{\mathrm{d}, \mathrm{e}, \mathrm{f}}$ & $<0.05$ \\
Amount of food eaten (g) & $1261 \pm 102$ & $1196 \pm 104$ & $1109 \pm 118$ & $1009 \pm 107$ & 0.08 \\
\hline
\end{tabular}

${ }^{a}$ Data are means, and the amino acids (AAs) have been presented in order of most to least concentrated, $n=16$;

$\mathrm{b}$ The infusions consisted of either saline (C), or of $2.1 \mathrm{~kJ} / \mathrm{min}(\mathrm{P} 2.1), 6.3 \mathrm{~kJ} / \mathrm{min}(\mathrm{P} 6.3)$, or $12.5 \mathrm{~kJ} / \mathrm{min}$ (P12.5) of hydrolysed whey protein, each infused at $4 \mathrm{~mL} / \mathrm{min}$ for $60 \mathrm{~min} ;{ }^{\mathrm{c}}$ Main effect of protein load was determined by one-way ANOVA and post-hoc comparisons between two loads were done using Bonferroni's correction; statistical significance was accepted at $p<0.05$; ${ }^{\mathrm{d}}$ Significantly different from $\mathrm{C}(p<0.05)$; ${ }^{\text {e }}$ Significantly different from P6.5 $(p<0.05){ }^{\mathrm{f}}{ }^{\mathrm{S}}$ Significantly different from P2.1 $(p<0.05) ;{ }^{\mathrm{g}}$ Trend for significant difference from P2.1 $(p<0.05)$.

\subsection{Relations between Insulin GLP-1 and Energy Intake with Plasma AA Concentrations}

AUCs $_{0-60 \min }$ of plasma concentrations for 19/20 AAs (the exception being cysteine) were related inversely to energy intake ( $R^{2}$ ranged between 0.09 and $\left.0.3, p<0.05\right)$, and directly to AUCs $\mathrm{s}_{0-60 \text { min }}$ of the serum/plasma concentrations of insulin $\left(R^{2}\right.$ ranged between 0.3 and $\left.0.6, p<0.01\right)$ and GLP-1 $\left(R^{2}\right.$ ranged between 0.2 and $0.6, p<0.05$ ), respectively. Figure 3 illustrates the strength of the relationships between the AUCs of each of the 20 AA profiles with energy intake as well as the AUCs of the insulin and GLP-1 profiles. The essential AAs, leucine, valine, isoleucine, lysine, methionine, and the conditionally-essential AA, tyrosine, yielded the strongest correlations with all three outcomes. 


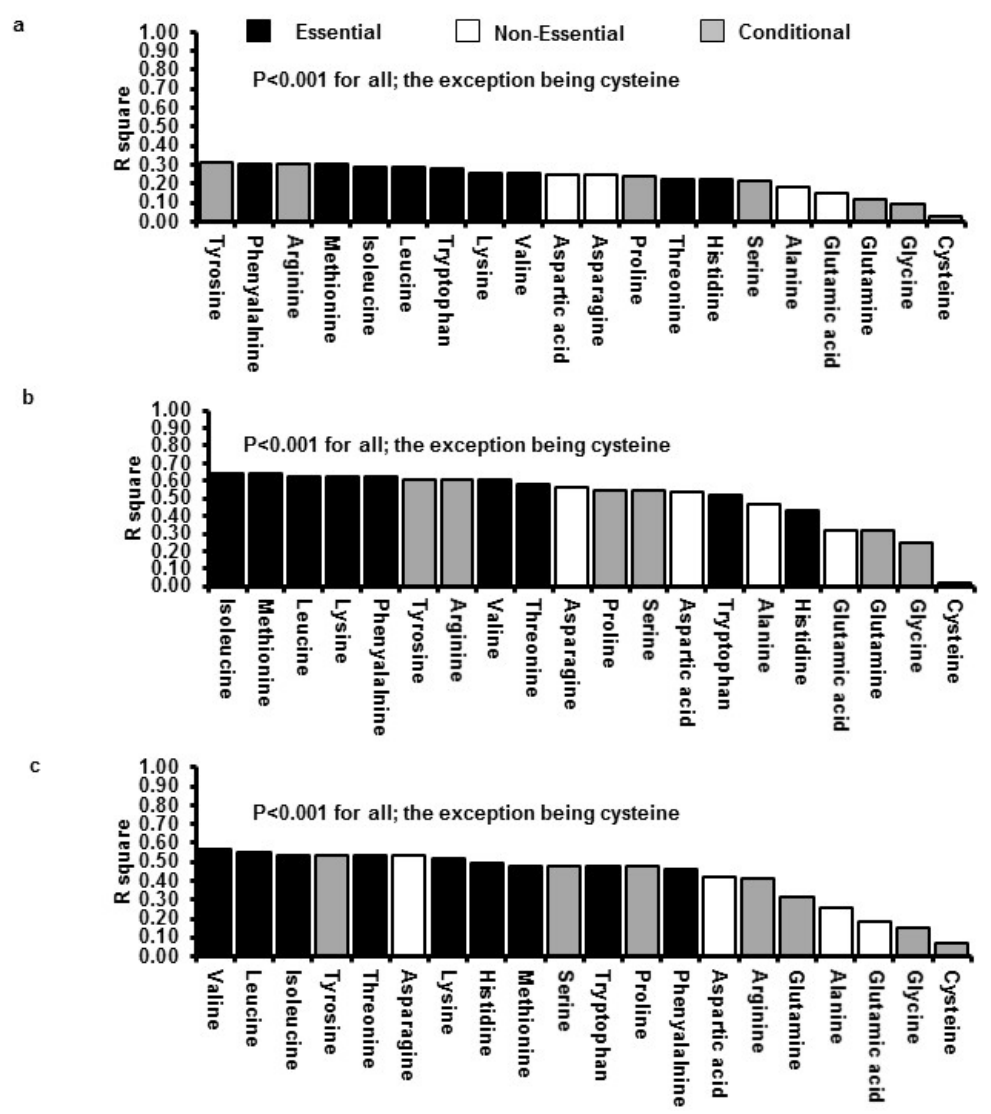

Figure 3. Relationships (ranked in order of strongest to weakest using $R^{2}$ values) between the AUC for each of the 20 amino acids with the AUC for (a) energy intake; (b) insulin; and (c) glucagon-like peptide-1 (GLP-1) following the $12.5 \mathrm{~kJ} / \mathrm{min}$ (P12.5) infusion of whey protein, administered at $4 \mathrm{~mL} / \mathrm{min}$ for $60 \mathrm{~min}$. Data are correlation coefficients for $n=16$ subjects. Statistical significance was accepted at $p<0.05$.

\section{Discussion}

This study has established that (i) increasing loads of ID whey protein hydrolysate led to load-dependent increases in the plasma concentrations of 19/20 free AAs over a 60-min period; (ii) plasma concentrations of the essential AAs reflected closely their concentrations in the infused whey protein, whereas the relationships were more variable for the non-essential and conditional AAs; and (iii) changes in plasma concentrations of the essential AAs, leucine, valine, isoleucine, methionine and lysine, and the conditionally-essential AA, tyrosine, were most closely associated with changes in energy intake, serum insulin and plasma GLP-1.

The first aim of this study was to determine the plasma concentrations of the 20 free AAs reaching the peripheral circulation in response to increasing loads of ID $18.1 \%$ hydrolysed whey protein. The findings in this study indicate that whey protein delivered to the duodenum at rates lower than $(2.1 \mathrm{~kJ} / \mathrm{min})$, comparable to $(6.3 \mathrm{~kJ} / \mathrm{min})$, and towards the upper end $(12.5 \mathrm{~kJ} / \mathrm{min})$ of the normal range for gastric emptying, increased, in a load-dependent manner, the plasma concentrations of 19/20 AAs. While plasma concentrations of the majority of AAs were increased by a whey protein load as low as $2.1 \mathrm{~kJ} / \mathrm{min}$, a load of $\geqslant 6.3 \mathrm{~kJ} / \mathrm{min}$ was required to increase alanine, glycine and tryptophan above control concentrations. Notably, cysteine was the only AA that was not increased by any load, confirming previous reports from studies using pig models indicating that cysteine is readily catabolised in the GI tract [22].

A limited number of studies have reported that concentrations of specific AAs reaching the peripheral circulation closely resemble their concentrations in the ingested protein source $[23,24]$. 
In contrast, other studies have found no relationships with any AA [25-27], or strong relationships only for the branched-chained AAs [13,14,28,29]. These discrepant observations may be accounted for by the use of high-protein drinks that included additional macronutrients, differing protein sources (i.e., dairy vs. plant protein, and also un-hydrolysed vs. hydrolysed proteins), oral administration (affecting gastric emptying), differences in the load of protein administered between individuals (e.g., prescription based on a ger $\mathrm{kg}$ total body weight or, per $\mathrm{kg}$ of fat free mass), and lack of standardisation of the meal immediately preceding the study. While our findings establish strong within-subject relationships between plasma concentrations of all essential AAs with their concentration in the infused protein load, there were also strong relationships with the conditional AAs, arginine, tyrosine and proline, while relationships for the non-essential AAs, aspartic acid, alanine and glutamic acid, or the conditional AAs, serine, glutamine, and glycine, were weak to moderate. Taken together, our observations highlight existing, although poorly appreciated, knowledge that plasma AA concentrations are modulated simultaneously by many factors including (i) the rates at which "free" AAs and di- and tri-peptides are taken up by the intestinal mucosa; (ii) the digestion and absorption of endogenous small intestinal protein; (iii) metabolic transformation during absorption (which is particularly extensive for the dicarboxylic AAs, glutamic and aspartic acids); and (iv) rates of uptake and release of AAs by the liver and other tissues [30].

A further aim of this study was to determine the relationships between plasma concentrations of the 20 free AAs with the changes in serum insulin and plasma glucagon-like peptide- 1 concentrations as well as energy intake in response to ID whey protein hydrolysate, reported previously [7]. Several studies have found modest associations between increased postprandial plasma concentrations for the essential AAs with either an increased release of some gut hormone (particularly GLP-1 and GIP) and/or insulin, and/or with a reduced energy intake [12-14]. A major strength of the current study was that the relationships of all 20 AAs with all three outcomes were assessed concurrently. This analysis was performed based on emerging evidence, in both rodents and humans, that leucine, glutamate, tryptophan, tyrosine and histidine (glutamate is a neurotransmitter and the latter three are all precursors of neurotransmitters), as well as lysine, threonine, phenylalanine, arginine and glutamine, can directly stimulate GLP-1 and insulin, and/or indirectly activate vagal pathways connecting the gut with the brain [31-33]. We have demonstrated that postprandial concentrations of all AAs, apart from cysteine, were correlated moderately with protein-induced suppression of energy intake, and strongly with postprandial concentrations of insulin and GLP-1. In addition, after ranking each AA based on the strength of their relationship with energy intake and AUCs of insulin and GLP-1 profiles, respectively, we observed that the essential AAs, leucine, valine, isoleucine, methionine and lysine, and the conditionally-essential AA, tyrosine, were the AAs that were most strongly correlated to all of these outcomes. While we recognise that relationships do not imply causality, our findings strongly indicate the need for further investigation of the role of these select AAs in the regulation of glucose homeostasis and energy intake using a study design that can directly determine the effects of isolated AAs.

Several aspects of our study design should be recognised when interpreting our results. Only healthy, lean males were included, and hence, the findings should not be generalised to females and obese people because they tend to be less sensitive to dietary manipulation [34], and insulin and GLP-1 concentrations and energy intake are affected by the menstrual cycle [35]. Although the total loads of protein delivered (i.e., 8, 24 and $48 \mathrm{~g}$, respectively) are representative of loads consumed in a snack or within a main meal, the observed findings may be different for other dairy or non-dairy protein sources, or if the protein was consumed orally or infused intragastrically. In addition, the effects of hydrolysed whey protein isolate are not necessarily generalizable to whole dairy and non-dairy protein foods which contain varying amounts of fat and carbohydrate and other dairy, or non-dairy, bioactives. 


\section{Conclusions}

In conclusion, this study provides new insights into the concentrations of 20 amino acids reaching the peripheral circulation following defined loads of whey protein that were infused intraduodenally to reflect the lower, middle and upper rate of the normal gastric emptying range for nutrients in human subjects. In addition, the study has identified relationships between the concentrations of some of these amino acids (particularly leucine, valine, isoleucine, lysine, methionine and tyrosine) with specific GI and gluco-regulatory functions, as well as energy intake. Collectively, these findings make an important contribution to a comprehensive understanding of the glycaemic and satiety effects of dietary protein for the management of obesity.

Acknowledgments: We thank Fonterra Research and Development Centre, Palmerston North, New Zealand, for providing the whey protein, and Kylie Lange and Judith Wishart, National Health and Medical Research Council of Australia Centre of Clinical Research Excellence in Translating Nutritional Science to Good Health, University of Adelaide, for statistical support and for performing the biochemical assays for insulin and glucagon like peptide-1, respectively. ND Luscombe-Marsh was supported by an NHMRC (National Health and Medical Research Council of Australia) New Investigator Project Grant (grant 627118, 2010-2014), AT Hutchison (formerly Ryan) by a Postgraduate Scholarship provided by the Faculty of Health Sciences, The University of Adelaide, S Soenen by a Royal Adelaide Hospital Mary Overton Fellowship (2011-2013), RE Steinert by a Royal Adelaide Hospital Mary Overton Fellowship (2012-2014), PM Clifton by a NMHRC Principal Research Fellowship (grant 1020594 2012-2016), and C Feinle-Bisset by NHMRC Senior Research Fellowships (grant 627002, 2010-2015; grant 1103020, 2016-2020). The research was funded by an NHMRC project grant to ND Luscombe-Marsh (grant 627118, 2010-2014).

Author Contributions: ND Luscombe-Marsh, PM Clifton, M Horowitz, and C Feinle-Bisset designed research; ND Luscombe-Marsh and AT Hutchison conducted research; ND Luscombe-Marsh analysed data, performed statistical analysis and wrote the manuscript; AT Hutchison, S Soenen, RE Steinert, PM Clifton, M Horowitz and $C$ Feinle-Bisset contributed to data interpretation and manuscript revision; and ND Luscombe-Marsh had primary responsibility for the final content of the manuscript. All authors read and approved the final manuscript.

Conflicts of Interest: The authors declare no conflict of interest.

\section{Abbreviations}

ID

GLP-1

CCK

GIP

PYY

AA

$\mathrm{AUC}_{0-60 m i n}$

P2.1

P6.3

P12.5

C

APD

VAS
intraduodenalGI: Gastrointestinal

glucagon-like peptide-1

cholecystokinin

glucose-dependent insulinotropic polypeptide

peptide $Y Y$

area amino acids

area under the curve from 0 to $60 \mathrm{~min}$

protein load $2.1 \mathrm{~kJ} / \mathrm{min}$

protein load $6.3 \mathrm{~kJ} / \mathrm{min}$

protein load $12.5 \mathrm{~kJ} / \mathrm{min}$

saline control

antropyloroduodenal motility

visual analog scale questionnaire

\section{References}

1. Luscombe-Marsh, N.D.; Noakes, M.; Wittert, G.A.; Keogh, J.B.; Foster, P.; Clifton, P.M. Carbohydrate-restricted diets high in either monounsaturated fat or protein are equally effective at promoting fat loss and improving blood lipids. Am. J. Clin. Nutr. 2005, 81, 762-772. [PubMed]

2. Weigle, D.S.; Breen, P.A.; Matthys, C.C.; Callahan, H.S.; Meeuws, K.E.; Burden, V.R.; Purnell, J.Q. A high-protein diet induces sustained reductions in appetite, ad libitum caloric intake, and body weight despite compensatory changes in diurnal plasma leptin and ghrelin concentrations. Am. J. Clin. Nutr. 2005, 82, 41-48. [PubMed] 
3. Clifton, P.M.; Bastiaans, K.; Keogh, J.B. High protein diets decrease total and abdominal fat and improve CVD risk profile in overweight and obese men and women with elevated triacylglycerol. Nutr. Metab. Cardiovasc. Dis. 2009, 19, 548-554. [CrossRef] [PubMed]

4. Parker, B.; Noakes, M.; Luscombe, N.; Clifton, P. Effect of a high-protein, high-monounsaturated fat weight loss diet on glycemic control and lipid levels in type 2 diabetes. Diabetes Care 2002, 25, 425-430. [CrossRef] [PubMed]

5. Pilichiewicz, A.N.; Papadopoulos, P.; Brennan, I.M.; Little, T.J.; Meyer, J.H.; Wishart, J.M.; Horowitz, M.; Feinle-Bisset, C. Load-dependent effects of duodenal lipid on antropyloroduodenal motility, plasma CCK and PYY, and energy intake in healthy men. Am. J. Physiol. Regul. Integr. Comp. Physiol. 2007, 293, R2170-R2178. [CrossRef] [PubMed]

6. Pilichiewicz, A.N.; Chaikomin, R.; Brennan, I.M.; Wishart, J.M.; Rayner, C.K.; Jones, K.L.; Smout, A.J.; Horowitz, M.; Feinle-Bisset, C. Load-dependent effects of duodenal glucose on glycemia, gastrointestinal hormones, antropyloroduodenal motility, and energy intake in healthy men. Am. J. Physiol. Endocrinol. Metab. 2007, 293, E743-E753. [CrossRef] [PubMed]

7. Ryan, A.T.; Feinle-Bisset, C.; Kallas, A.; Wishart, J.M.; Clifton, P.M.; Horowitz, M.; Luscombe-Marsh, N.D. Intraduodenal protein modulates antropyloroduodenal motility, hormone release, glycemia, appetite, and energy intake in lean men. Am. J. Clin. Nutr. 2012, 96, 474-482. [CrossRef] [PubMed]

8. Houghton, L.A.; Read, N.W.; Heddle, R.; Horowitz, M.; Collins, P.J.; Chatterton, B.; Dent, J. Relationship of the motor activity of the antrum, pylorus, and duodenum to gastric emptying of a solid-liquid mixed meal. Gastroenterology 1988, 94, 1285-1291. [PubMed]

9. Horowitz, M.; Edelbroek, M.A.L.; Wishart, J.M.; Straathof, J.W. Relationship between oral glucose-tolerance and gastric-emptying in normal healthy-subjects. Diabetologia 1993, 36, 857-862. [CrossRef] [PubMed]

10. Ma, J.; Stevens, J.E.; Cukier, K.; Maddox, A.F.; Wishart, J.M.; Jones, K.L.; Clifton, P.M.; Horowitz, M.; Rayner, C.K. Effects of a protein preload on gastric emptying, glycemia, and gut hormones after a carbohydrate meal in diet-controlled type 2 diabetes. Diabetes Care 2009, 32, 1600-1602. [CrossRef] [PubMed]

11. Ryan, A.T.; Luscombe-Marsh, N.D.; Saies, A.A.; Little, T.J.; Standfield, S.; Horowitz, M.; Feinle-Bisset, C. Effects of intraduodenal lipid and protein on gut motility and hormone release, glycemia, appetite, and energy intake in lean men. Am. J. Clin. Nutr. 2013, 98, 300-311. [CrossRef] [PubMed]

12. Floyd, J.C., Jr.; Fajans, S.S.; Conn, J.W.; Knopf, R.F.; Rull, J. Insulin secretion in response to protein ingestion. J. Clin. Investig. 1966, 45, 1479-1486. [CrossRef] [PubMed]

13. Veldhorst, M.A.; Nieuwenhuizen, A.G.; Hochstenbach-Waelen, A.; Westerterp, K.R.; Engelen, M.P.; Brummer, R.J.; Deutz, N.E.; Westerterp-Plantenga, M.S. Effects of complete whey-protein breakfasts versus whey without GMP-breakfasts on energy intake and satiety. Appetite 2009, 52, 388-395. [CrossRef] [PubMed]

14. Nilsson, M.; Holst, J.J.; Bjorck, I.M. Metabolic effects of amino acid mixtures and whey protein in healthy subjects: Studies using glucose-equivalent drinks. Am. J. Clin. Nutr. 2007, 85, 996-1004. [PubMed]

15. Fromentin, G.; Darcel, N.; Chaumontet, C.; Marsset-Baglieri, A.; Nadkarni, N.; Tome, D. Peripheral and central mechanisms involved in the control of food intake by dietary amino acids and proteins. Nutr. Res. Rev. 2012, 25, 29-39. [CrossRef] [PubMed]

16. Anderson, G.H.; Tecimer, S.N.; Shah, D.; Zafar, T.A. Protein source, quantity, and time of consumption determine the effect of proteins on short-term food intake in young men. J. Nutr. 2004, 134, 3011-3015. [PubMed]

17. Pal, S.; Ellis, V. The acute effects of four protein meals on insulin, glucose, appetite and energy intake in lean men. Br. J. Nutr. 2010, 104, 1241-1248. [CrossRef] [PubMed]

18. Silk, D.B.; Grimble, G.K.; Rees, R.G. Protein digestion and amino acid and peptide absorption. Proc. Nutr. Soc. 1985, 44, 63-72. [CrossRef] [PubMed]

19. Stanton, C.; Fitz Gerald, R.J.; Donnelly, W.J.; O'Connor, P. Development of technologies for separation and functional improvement of individual milk protein fractions. Available online: http:/ / www.teagasc.ie/research/reports/dairyproduction/4216/eopr-4216.asp (accessed on 30 November 2015).

20. Nair, N.S.; Brennan, I.M.; Little, T.J.; Gentilcore, D.; Hausken, T.; Jones, K.L.; Wishart, J.M.; Horowitz, M.; Feinle-Bisset, C. Reproducibility of energy intake, gastric emptying, blood glucose, plasma insulin and cholecystokinin responses in healthy young males. Br. J. Nutr. 2009, 101, 1094-1102. [CrossRef] [PubMed] 
21. Cohen, S.A. Amino Acid Analysis Using Precolumn Derivatisation with 6-Aminoquino lyl-n-Hydroxysuccinimidyl Carbamate; Humana Press: Totowa, NJ, USA, 2001; pp. 39-47.

22. Shoveller, A.K.; Stoll, B.; Ball, R.O.; Burrin, D.G. Nutritional and functional importance of intestinal sulfur amino acid metabolism. J. Nutr. 2005, 135, 1609-1612. [PubMed]

23. Adibi, S.A.; Gray, S.J. Intestinal absorption of essential amino acids in man. Gastroenterology 1967, 52, 837-845. [PubMed]

24. Hegarty, J.E.; Fairclough, P.D.; Moriarty, K.J.; Clark, M.L.; Kelly, M.J.; Dawson, A.M. Comparison of plasma and intraluminal amino acid profiles in man after meals containing a protein hydrolysate and equivalent amino acid mixture. Gut 1982, 23, 670-674. [CrossRef] [PubMed]

25. Frame, E.G. The levels of individual free amino acids in the plasma of normal man at various intervals after a high-protein meal. J. Clin. Investig. 1958, 37, 1710-1723. [CrossRef] [PubMed]

26. Yearick, E.S.; Nadeau, R.G. Serum amino acid response to isocaloric test meals. Am. J. Clin. Nutr. 1967, 20, 338-344. [PubMed]

27. Longenecker, J.B.; Hause, N.L. Relationship between plasma amino acids and composition of the ingested protein. II. A shortened procedure to determine plasma amino acid (PAA) ratios. Am. J. Clin. Nutr. 1961, 9, 356-362. [PubMed]

28. Calbet, J.A.; MacLean, D.A. Plasma glucagon and insulin responses depend on the rate of appearance of amino acids after ingestion of different protein solutions in humans. J. Nutr. 2002, 132, 2174-2182. [PubMed]

29. Hall, W.L.; Millward, D.J.; Long, S.J.; Morgan, L.M. Casein and whey exert different effects on plasma amino acid profiles, gastrointestinal hormone secretion and appetite. Br. J. Nutr. 2003, 89, 239-248. [CrossRef] [PubMed]

30. Matthews, D.M. Intestinal absorption of amino acids and peptides. Proc. Nutr. Soc. 1972, 31, $171-177$. [CrossRef] [PubMed]

31. Uneyama, H.; Niijima, A.; San Gabriel, A.; Torii, K. Luminal amino acid sensing in the rat gastric mucosa. Am. J. Physiol. Gastrointest. Liver Physiol. 2006, 291, G1163-G1170. [CrossRef] [PubMed]

32. Morrison, C.D.; Reed, S.D.; Henagan, T.M. Homeostatic regulation of protein intake: In search of a mechanism. Am. J. Physiol. Regul. Integr. Comp. Physiol. 2012, 302, R917-R928. [CrossRef] [PubMed]

33. Greenfield, J.R.; Farooqi, I.S.; Keogh, J.M.; Henning, E.; Habib, A.M.; Blackwood, A.; Reimann, F.; Holst, J.J.; Gribble, F.M. Oral glutamine increases circulating glucagon-like peptide 1, glucagon, and insulin concentrations in lean, obese, and type 2 diabetic subjects. Am. J. Clin. Nutr. 2009, 89, 106-113. [CrossRef] [PubMed]

34. Rolls, B.J.; Kim-Harris, S.; Fischman, M.W.; Foltin, R.W.; Moran, T.H.; Stoner, S.A. Satiety after preloads with different amounts of fat and carbohydrate: Implications for obesity. Am. J. Clin. Nutr. 1994, 60, 476-487. [PubMed]

35. Brennan, I.M.; Feltrin, K.L.; Nair, N.S.; Hausken, T.; Little, T.J.; Gentilcore, D.; Wishart, J.M.; Jones, K.L.; Horowitz, M.; Feinle-Bisset, C. Effects of the phases of the menstrual cycle on gastric emptying, glycemia, plasma GLP-1 and insulin, and energy intake in healthy lean women. Am. J. Physiol. Gastrointest. Liver Physiol. 2009, 297, G602-G610. [CrossRef] [PubMed]

(C) 2016 by the authors; licensee MDPI, Basel, Switzerland. This article is an open access article distributed under the terms and conditions of the Creative Commons by Attribution (CC-BY) license (http://creativecommons.org/licenses/by/4.0/). 